Archived version from NCDOCKS Institutional Repository http://libres.uncg.edu/ir/asu/

Pine, J. C., \& Marx, B. D. (1997). Utilizing state hazardous materials transportation data in hazardous analysis. Journal of hazardous materials, 54(1), 113-122. (ISSN: 0304-3894)

Published by Elsevier, and is available from http://www.journals.elsevier.com/journal-ofhazardous-materials/

\title{
Utilizing state hazardous materials transportation data in hazardous analysis
}

\author{
John C. Pine, Brian D. Marx
}

\begin{abstract}
Local communities in the United States are required by federal law to assess and plan for risks posed by the transportation of hazardous chemicals in the community. Two sources of data relating to the transportation of hazardous chemicals by motor carrier were examined to determine their value in the hazardous analysis process. Local road side transportation surveys were examined and compared with state truck inventory data drawn on a national basis by the United States Department of Transportation. Statistical analyses of the two data sets suggests that state data collected on a national basis by the US Department of Transportation's truck inventory use survey was not representative of the hazardous chemical data transportation profiles collected at the local road side surveys. The state truck inventory use survey data provides a statewide perspective of motor carrier hazardous materials shipments. The authors determined that additional commodity flow studies should be completed to provide a more precise view of local chemical hazards presented by motor carrier shipments of hazardous chemicals.
\end{abstract}

\section{Introduction}

Chemical processing is a major part of the Louisiana economy. The Transportation and Environmental Safety Section of the Department of Public Safety and Corrections (DPS) reports that approximately $25 \%$ of regulated hazardous materials in the United States are either produced, used, stored, or transported within the boundaries of the State of Louisiana. In addition, major transportation routes including rail lines, Interstates, pipelines, waterways, and ports are located within the boundaries of the state. Louisiana has four interstate highways, four major international ports, transcontinental rail and pipelines. Each of these major transportation systems carries a 
significant quantity of hazardous chemicals through the state. From these transportation routes, motor carrier trucks carry more than $60 \%$ of all hazardous materials transported domestically and are responsible for many hazardous materials spills.

Traditionally, emergency planning by local communities has focused on chemical facilities in the community since extensive information relating to chemical inventories and processes at the site is available. However, information on shipments of hazardous chemicals on local transportation routes is not readily available on a national, state, or local level [l]. Shippers are not required to report type of chemical, the container, and routes at the national, state, or local level [2]. Analysis of the risks presented by the transportation of hazardous materials thus presents a very different risk than a fixed facility. Detailed information on shipments is not available on a national, regional, or local level in contrast with fixed facility inventories. In addition the geographic area that could be affected by a spill is widespread throughout community [3] and could occur at numerous intersections or along a route. The environmental and human health risks associated with spills of hazardous materials in transit requires extensive information as with fixed facilities; without this information, effective planning cannot be accomplished $[4,5]$. Because of the extensive volume of chemicals processed and transported within the state, Louisiana faces a significant need to obtain information on the nature and scope of chemicals in transit so that the emergency management system at the state and local levels are prepared to respond to hazardous chemical transportation accidents.

Louisiana not only has a special need to plan and respond effectively to hazardous chemical incidents, but it also has the capacity to enhance state and local emergency planning and response efforts. The Louisiana State Emergency Response Commission (SERC) has supported the development of a state and local emergency planning system. Louisiana's Local Emergency Planning Committees (LEPC) are a part of this emergency management system and have been provided detailed data on the chemical inventories for facilities in the community. This data is necessary to prepare and maintain comprehensive hazardous chemical emergency management plans. Unfortunately, information on chemicals transported within or through the state has been difficult to identify. Louisiana is unique in not only having the need to plan and respond effectively to hazardous chemical emergencies, but also a foundation for a systematic effort to improve local planning and response efforts.

The United States Environmental Protection Agency (EPA) has provided support to the Louisiana SERC and LEPCs in identifying high hazard areas in the state and in assisting LEPCs in improving local hazardous materials emergency response plans. The LEPCs conducted a comprehensive hazards analysis utilizing Tier2 chemical inventory records, Toxic Release Inventory data, and EPA's Emergency Response Notification System (ERNS) reports of incidents involving chemical accidents. Unfortunately, limited information is available on the transportation by motor carrier of hazardous chemicals.

\section{Available data and methodology}


To ensure that a local emergency response plan is complete, the LEPC must take into account the nature and extent hazardous materials are transported by motor carriers in the community. One approach although limited is to assume that local facility inventories of extremely hazardous chemicals are transported on local highways. This process fails to identify hazardous materials shipped through the community apart from those included in local inventories. Local emergency plans thus may be inadequate. LEPCs having major transportation routes in the community should thus look beyond facility inventories of hazardous materials and identify those that transported through their community.

The collection of data relating to the transportation of hazardous chemicals has in the past been obtained through the completion of a local commodity flow roadside survey. These surveys when conducted under the procedures recommended by the United States Department of Transportation, provide a local community an excellent snapshot of risks associated with the transportation of hazardous chemicals [6]. Using the faculty and students of the Environmental Sciences Department of McNeese State University, the Calcasieu parish Local Emergency Planning Committee and Parish Office of Emergency Management conducted roadside commodity flow studies in 1989 of hazardous materials transported in the parish in 1989 and again in 1994. The results of the surveys was used as a part of the Calcasieu parish analysis of chemical hazards and form the basis for revising the parish emergency operations plan.

In addition to the local surveys, the United States Department of Commerce conducts a Transportation Truck Inventory and Use Survey (TIUS) every five years $[7,8]$. Data reflecting the type of vehicle and cargo carried is obtained from a sample of shippers in each state within the United States. Cargo information collected from this survey includes data on hazardous materials transported by the trucks.

The question presented in this study was to determine whether or not the US Department of Commerce TIUS reflected hazardous materials transported within a community. Data from the TIUS 1987 and 1992 surveys were compared with local commodity flow roadside surveys conducted in Calcasieu parish in 1989 and 1994. If the TIUS data was an accurate reflection of a local roadside survey, then the TIUS could be used by local community emergency planning committees and emergency response personnel to plan and prepare for chemical risks presented by hazardous chemical transported through the community. Details of these data sources will be provided along with a variety of statistical analyses and discussion in the subsequent sections.

\section{The Calcasieu parish roadside surveys}

The objective of the Calcasieu parish transportation road side surveys conducted in 1989 and 1994 was to determine the nature and extent of hazardous materials transported in the parish. The results of the survey provided cross-sectional data of the 
type of hazardous chemicals transported, the container used in transportation, and the frequency of hazardous chemicals shipped [9]. Two areas in Calcasieu parish were selected for the 1989 and 1994 roadside surveys. An area along Interstate 10 in Calcasieu parish between Sulphur and Lake Charles was selected as well as the perimeter highway around the City of Lake Charles (Interstate 210 Loop). Although other roads and highways are used for transporting hazardous materials, the heaviest flow by far was expected for the Interstate 10 and Interstate 210 routes. These locations were well suited for the road side survey for each route is a major transportation corridor through the parish. For purposes of this study, the I-210 loop around Lake Charles was not included in the analysis, because few trucks carrying hazardous chemicals were identified here in these surveys.

The 1989 survey was conducted over a $38 \mathrm{~h}$ period. The second survey was carried out in 1994 but limited to a $12 \mathrm{~h}$ period, since heavy rain storms made observation of the truck placard cards difficult. In addition, the rain posed a danger to the survey workers; the slick highways and limited visibility created a dangerous condition for the workers. During both the 1989 and 1994 roadside survey period, students from McNeese State University's Environmental Science Program were trained to identify vehicles carrying hazardous materials. The students made a record of vehicles which were marked with United States Department of Transportation (US DOT)/United Nations hazardous materials placard numbers. This classification system is described in Appendix A.

In 1989 , a total of 1,297 placarded trucks were recorded at the Interstate 10 roadside survey site (while as only four placarded trucks were observed on Interstate 210 Loop). A total of 435 placarded trucks were observed during the 1994 survey along the main survey point along Interstate 10 (whereas only three placard trucks were observed on Interstate 210). Trucks with hazardous chemicals were identified using the US DOT truck placard number.

Although motor transporters shipping hazardous materials are required to display the US DOT placard on the outside of the truck, it is possible that motor carriers fail to display the required placard. This could occurs even though the carrier would face significant fines from state inspectors who discovered that hazardous cargo placards had not been displayed.

\section{Truck inventory use survey}

The United States Department of Commerce began the Census of Transportation in 1963 as a set of surveys covering travel, transportation of commodities, and trucks. The 1987 and 1992 Census of Transportation includes the Truck Inventory and Use Survey (TIUS); this survey provides data on the physical and operational characteristics of the nation's truck population [7,5]. The TIUS is based on a probability sample of private and commercial trucks registered or licensed in each state during 1987 for the first TIUS and 1992 for the most recent survey. 
The US Department of Transportation (DOT) has been concerned with the safe transportation of hazardous materials in interstate commerce and established a classification system for containers and packages used in the transportation process. The data in the TIUS is based on this hazardous materials classification system. DOT along with other federal agencies and various professional organizations in the United States developed classes of hazardous materials so as to provide a system for categorizing hazards associated with chemical substances. The DOT hazardous materials classifications include the following categories: flammable liquid; flammable compressed gas; combustible liquid; flammable solids; oxidizer, organic peroxide; corrosive; poisons; and other regulated material.

The TIUS data used in this study was based on a sample of 12800 trucks registered in Louisiana for the 1987 survey and 13200 for the 1992 survey. The 1987 and 1992 TIUS samples were drawn from a universe of truck registrations in the state between July 1 and December 31 in 1987 for the first set of TIUS data and 1992 for the second set. The trucks were selected using a stratified, random sample design. Truck owners as identified by state registration records and asked to complete a report examining the nature of hazardous cargo shipped by their trucks.

\section{Statistical analyses and results}

A statistical analysis of the hazardous materials data was completed using the 1989 and 1994 Calcasieu data and the 1987 and 1992 TIUS data. An investigation of the distribution of nine classes of hazardous materials (flammable liquid, flammable gas, combustible liquid, corrosive, nonflammable gas, poison, oxidizer, flammable solid, and other) was completed for each of the two data sets, i.e., the TIUS and the Calcasieu parish roadside surveys. For the following analyses, several classes were pooled (oxidizer and flammable solid into the other class) due to the low frequencies in the data. Such pooling is done to meet certain testing assumptions.

The profiles of hazardous materials are well explained using a multinomial distribution, i.e., each transported material has a certain, perhaps unknown, probability of being designated as one of these classes such that the probabilities sum to one. One primary interest with such multinomial data is drawing inference regarding the structure of the probabilities of each class, i.e., do our samples of data agree with certain relevant hypotheses regarding class probabilities? One of two interesting hypothesis was raised to see if the data suggest that the profile of the seven multinomial probabilities, associated with hazardous classification, are homogenous in the Calcasieu parish data from the year 1989 to the year 1994. Fig. 1 shows that the most common type of hazardous chemical transported through Calcasieu parish included flammable liquids (31\% in 1989 and 34\% in 1994), followed by flammable gas (20\% in 1989 and $14 \%$ in 19941, corrosives (18\% in 1989 and 19\% in 1994), and combustible liquids (15\% in 1989 and $12 \%$ in 1994). 
Given the $1989(\mathrm{~N}=1297)$ and the $1994(\mathrm{~N}=435)$ Calcasieu parish data in Fig. 1, a two-way table or contingency table can be constructed where the entries are counts. In this data, we have random samples taken from sub-populations defined by the rows of the contingency table, namely years. We are interested in testing homogeneity of the column or hazardous material distribution, i.e., the examining if the percentage probabilities across years are the same (are not statistically significantly different) by hazardous material. Such a test can be performed using Pearson's Statistic which follows a Chi-square distribution with $(r-1) \times(c-1)$ degrees of freedom. We have $r=2$ rows and $\mathrm{c}=7$ columns yielding 6 degrees of freedom for our data. Note that pooled oxidizer

J.C. Pine, B.D. Marx / Journal of Hazardous Materials 54 (1997) 113-122

Class

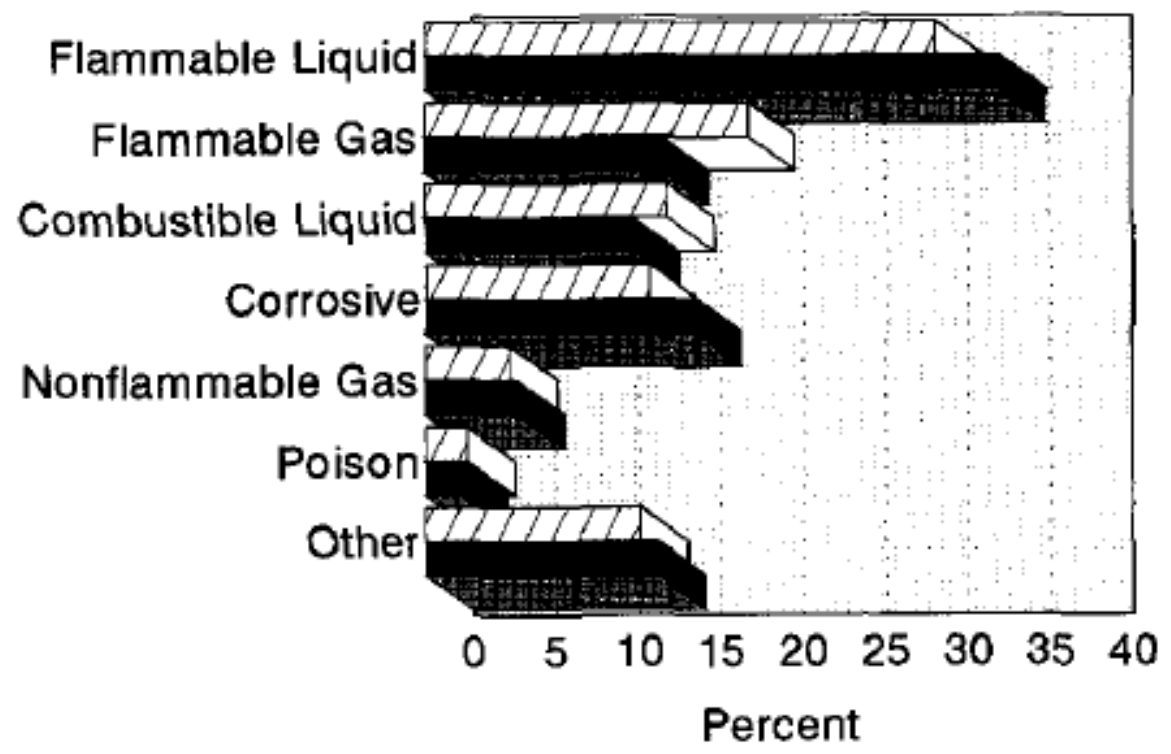

$\square 1989$

\section{$1989 \mathrm{~N}=1,297 \quad 1994 \mathrm{~N}=435$}

Fig. 1. Calcasieu parish roadside surveys, 1989 and 1994.

and flammable solid were consolidated into the other category. The Pearson's Statistic for the above table is 10.309 ( $p$-value $=0.112$ ). Thus we do not have sufficient evidence to reject homogeneity across years, i.e., we do not have compelling evidence of heterogeneity. The distributions of chemicals transported in 1989 and 1994 using the US DOT classifications were similar. The risks presented by hazardous chemicals transported through Calcasieu parish in 1989 were similar to the type of hazardous chemicals transported in 1994.

In a similar fashion, the 1987 and 1992 Louisiana TIUS were compared. This second hazardous materials two-way contingency table can be constructed from Fig. 2 . The 
Louisiana TIUS survey provides the hazardous materials cargo profiles across two different years including 1987 and 1992. Pearson's Statistic is a colossal 3374.294 with 8 degrees of freedom providing compelling evidence of heterogeneity of these profiles across years, with a p-value of less than 0.0001 . Closer scrutiny of Fig. 2 helps us

\section{Class}

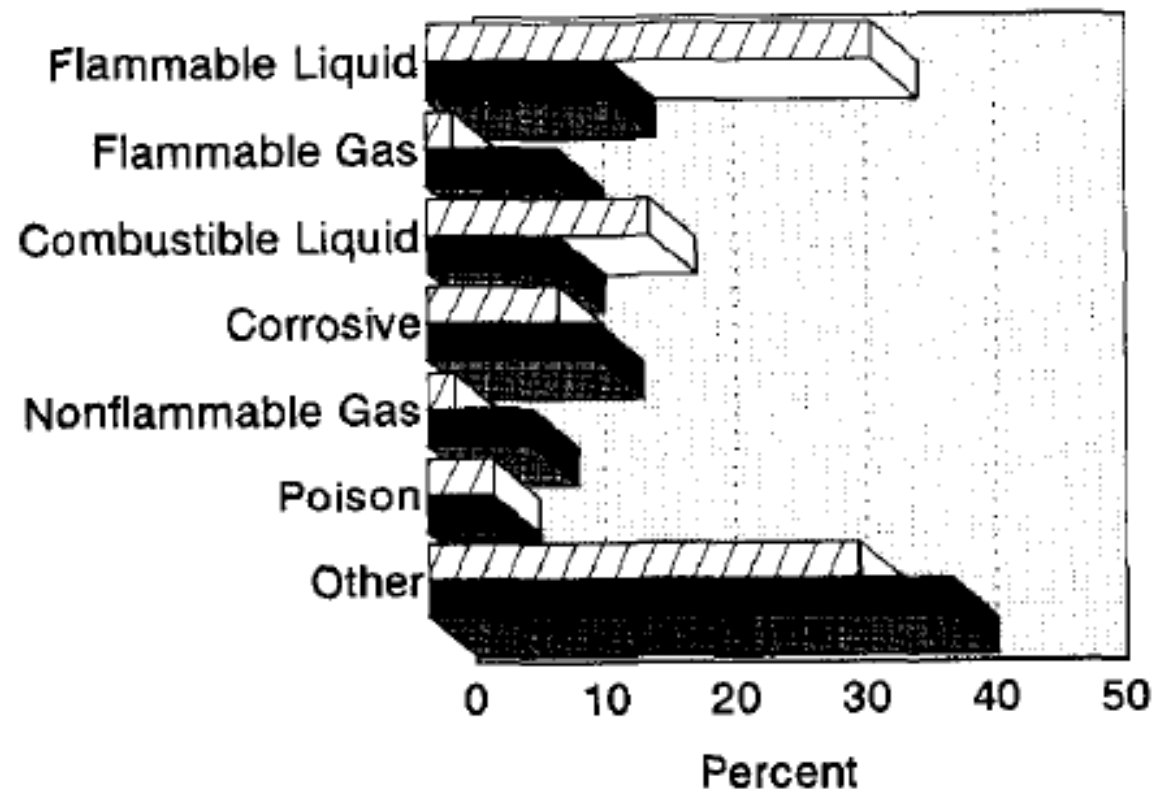

Fig. 2. Truck inventory and use surveys, 1987 and 1992. 

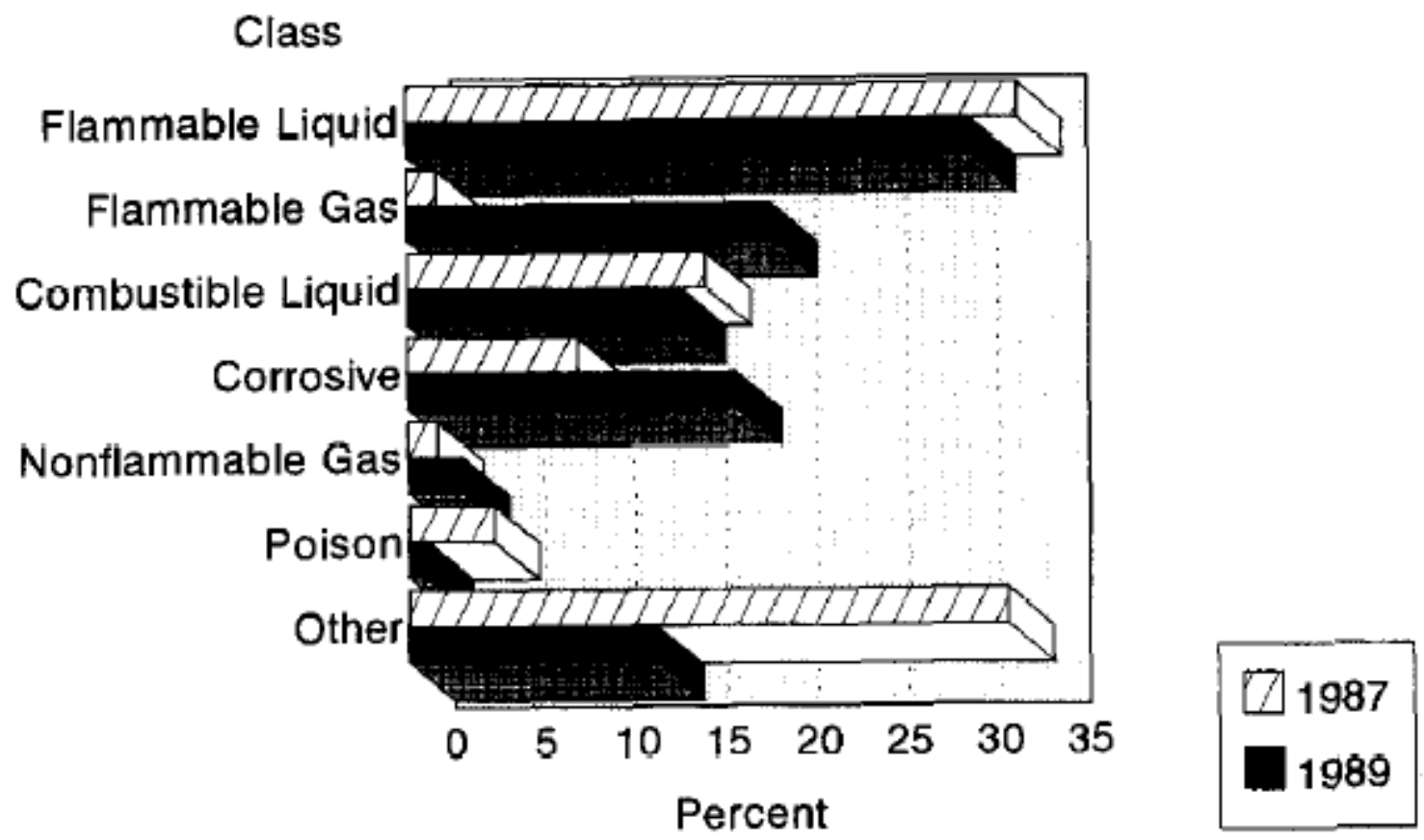

Fig. 3. 1987 TIUS and 1989 Calcasieu parish surveys.

understand the differences across the years 1987 and 1992. From 1987 to 1992, the analysis found a significant decrease in the Louisiana TIUS in flammable liquids (33\% to $14 \%$ ) and combustible liquids ( $17 \%$ to lo\%), respectively. On the other hand, significant increases were found in flammable gas (2\% to lo\%), nonflammable gas ( $2 \%$ to $8 \%)$, and corrosives (10\% to $13 \%)$, respectively, were found during the same period.

The comparison shows that the type of hazardous chemical transported in 1987 is highly statistically different from the 1994 data.

When the Calcasieu and TIUS surveys were analyzed together, a slightly different perspective of the 1989 and 1994 Calcasieu parish data can be gained by comparing the Calcasieu 1989 and 1994 profile distributions directly to the 1987 and 1992 TIUS Louisiana survey data as reflected in Fig. 3 and Fig. 4. The testing procedure used for these comparisons considers the TIUS data as a known standard, then tests whether or not either the 1989 or 1994 Calcasieu parish data are a reflective samples from these standards, respectively. 

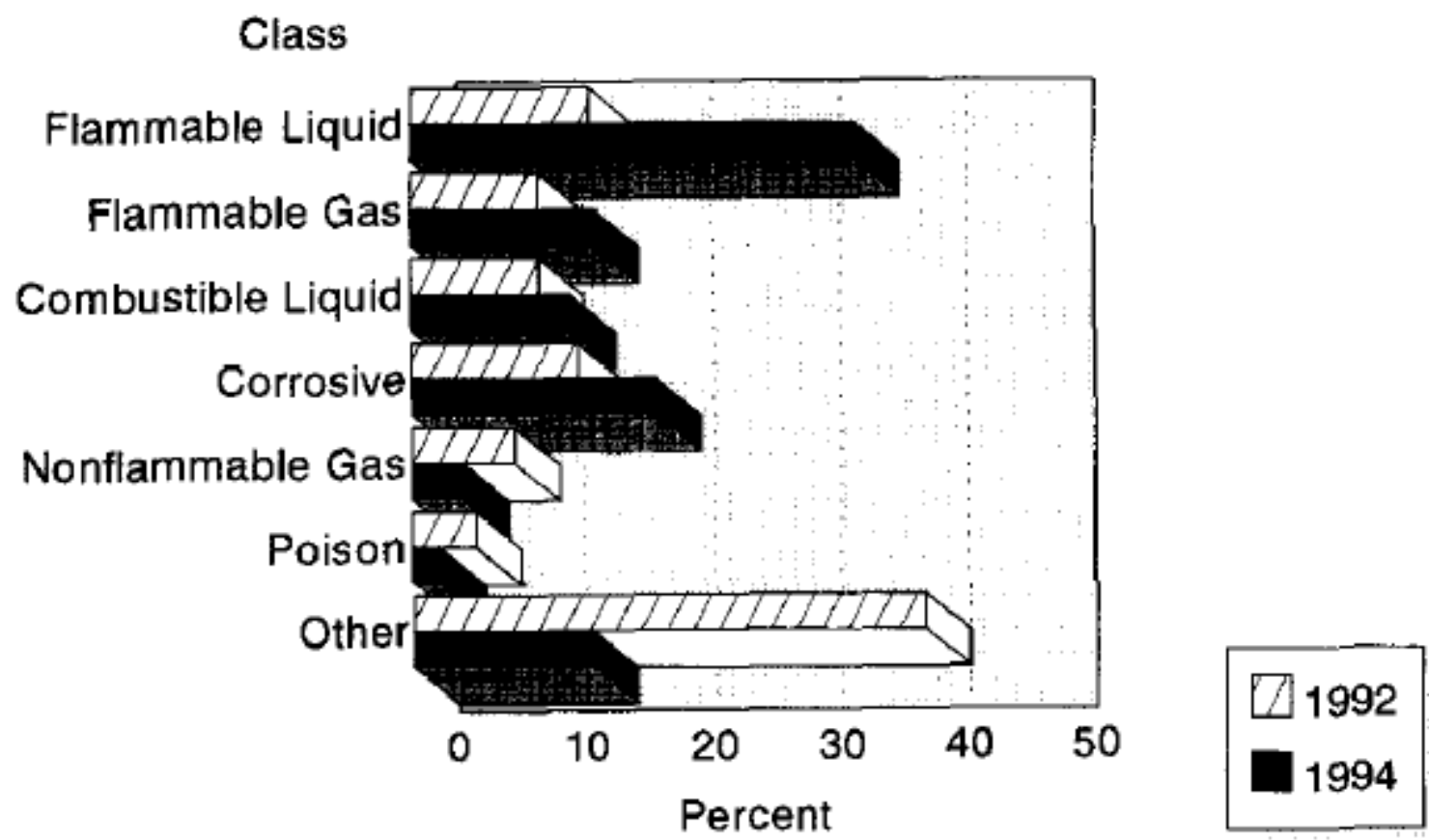

Fig. 4. 1992 TIUS and 1994 Calcasieu parish surveys.

In all six cases of comparisons (1989 and 1992 Calcasieu data versus the three TIUS Surveys), the Calcasieu profiles differed significantly from each TIUS survey. All the differences were extremely convincing, having $p$-values less than 0.000001 . Recall that the 1989 Calcasieu profile does not differ significantly from the 1994 Calcasieu data. Despite consistencies within Calcasieu parish surveys, we do find compelling evidence that the Calcasieu profiles are not reflective of the of the Louisiana TIUS survey data. In fact looking more closely at Fig. 3, the Calcasieu 1989 and 1987 TIUS surveys flammable gas, nonflammable gas, and corrosives are significantly higher in the Calcasieu parish survey than the Louisiana 1987 TIUS survey. When comparing the 1994 Calcasieu survey to the 1992 Louisiana TIUS survey, we found that flammable liquids, flammable gas, combustible liquid, and corrosives were clearly significantly higher in Calcasieu parish than in the Louisiana TIUS data. The reversal was found in nonflammable gas.

\section{Conclusions}

The United States Department of Commerce TIUS and Calcasieu parish data reflect two completely different types of surveys. The Calcasieu roadside survey includes trucks

with specific hazardous materials placards passing a specified point in a parish, regardless of the origination or destination of the truck. The TIUS, however, is drawn from state registered owners of the vehicle in a state and which were identified by the owner as carrying hazardous materials. When the two surveys were compared no 
similarities in the percentage of trucks carrying hazardous chemicals in Louisiana were seen. The TIUS provides a general view of chemical risks on a state or national level or a snapshot of state registered trucks carrying hazardous materials. It provides a state perspective of trucks carrying hazardous materials which may or may not be present in a specific local community. The TIUS although useful in as a general view of hazardous materials risks, may not be the most precise indicator of the nature risks of local shipments of trucks carrying hazardous materials. A more precise view of the local condition of hazardous materials transported by motor carriers through a community may need to be obtained through the local commodity flow study.

Local emergency managers have struggled to identify sources of data on the transportation of hazardous chemicals in their community. The TIUS data which is collected on a state and national basis, may be used in a general examination of risks presented by hazardous materials transported by motor carriers. Local emergency managers may want to go beyond the general view provided by the TIUS. This study suggests that a local commodity flow study could identify specific chemical risks in the community that were not evident in the TIUS.

Although roadside surveys are time consuming and require the commitment of a team of trained dedicated observers, few alternatives appear to be available to local emergency managers. If a local community desires a precise view of hazardous materials transportation risks, then a local commodity flow study accomplished through a roadside survey appears to be the only option.

If the risks associated with the motor carrier transportation of hazardous chemicals is to be understood and effective plans developed to effectively respond to accidental releases resulting from accidents, local emergency management officials and members of LEPCs should initiate commodity flow studies. Without commodity flow studies, communities with major highways may have unknown hazardous chemical risks. They would be well advised to identify these risks and prepare for possible transportation accidents of the chemicals.

\section{Acknowledgements}

The authors recognize the contribution of Norman Bourdeau, Office of Emergency Preparedness, Calcasieu Parish Police Jury, and Bruce Wyman, Environmental Sciences, McNeese State University for their efforts in planning and conducting the Calcasieu Parish Roadside surveys. The authors would like to thank the Editor, Gary F. Bennett, and the anonymous referees for their constructive review.

\section{Appendix A. US Department of Transportation Hazardous Materials Classification System 49 CFR 171-179}

Explosive: any chemical compound, mixture, or device, the primary of common purpose of which is to function by explosion, i.e., with substantially instantaneous release of gas and heat. 
Blasting agent: a material designed for blasting which has been found to be so insensitive that there is very little probability of accidental initiation to explosion or of transition from deflagration to detonation (the material is capable of exploding under very special conditions, but these conditions are unlikely to occur in transportation, even in the event of an accident.

Flammable liquid: refers to any liquid, with certain limitations and exceptions, that has a 'closed-cup' flash point below 100 degrees.

Combustible liquid: refers to any liquid that has a flash point of 100 degrees Fahrenheit or more but no higher than 200 degrees.

Flammable solids: any solid materials other than one classed as an explosive, which, under conditions normally incident to transportation is liable to cause fires through friction, retained heat from manufacturing or processing, or which can be ignited readily and when ignited bum so vigorously and persistently as to create a serious transportation hazard.

Oxidizer: is a substance that yields oxygen readily to stimulate the combustion of organic matter.

Corrosive: a liquid or solid that causes visible destruction or irreversible alterations in human skin tissue at the site of contact, or in the case of leakage from its packaging, a liquid that has a severe corrosion rate on steel.

Flammable compressed gas: is a compressed gas that has a lower flammable limit concentration of $13 \%$ or less by volume in air, or which has a flammable range of greater than $12 \%$, or which behaves in a pre-specified manner in a flammability testing apparatus.

Poisons: materials are divided into three groups in DOT regulations according to their degree of hazard in transportation. Poison A substances are poisonous gases or liquids of such a nature that a very small amount of the gas, or vapor of the liquid, mixed with are is dangerous to life. Poison B materials are liquids or solids, other than Class A poisons or irritating materials, which are known to be so toxic to man as to afford a hazard to health during transportation.

\section{References}

[1] Assessing Hazardous Materials Transportation in the Kanawha Valley, Emergency Response Planning and Management, National Institute for Chemical Studies, Charleston, WV. 
[2] SARA Title III (EPCRA) and Conducting a Commodity Flow Study, Hazards Analysis on the Move, Office of Solid Waste and Emergency Response, US Environmental Protection Agency, EPA 550-F-93-004 October 1993.

[3] Hazardous Materials Emergency Planning Guide. National Response Team, Washington, DC., 1986.

[4] Handbook of Chemical Hazard Analysis Procedures. Federal Emergency Management Agency, US Department of Transportation, and U.S. Environmental Protection Agency. Washington, D.C.

[5] Technical Guidance for Hazards Analysis: Emergency Planning for Extremely Hazardous Substances. U.S. Environmental Protection Agency, Federal Emergency Management Agency, and US Department of Transportation. Washington, DC., 1987.

[6] Guide for the Development of State and Local Emergency Operations Plans. Federal Emergency Management Agency, Washington, D.C., 1988.

[7] Truck Inventory and Use Survey, 1987 Census of Transportation, US Department of Commerce, Bureau of the Census, Washington, D.C., 1989.

[8] Truck Inventory and Use Survey, 1992, Census of Transportation, US Department of Commerce, Bureau of the Census, Washington, D.C. 1992.

[9] Truck Transportation of Hazardous Materials through Calcasieu Parish, Louisiana, Bruce Wyman and Norman Bourdeau, A report to the Calcasieu Parish Local Emergency Planning Committee, Lake Charles, LA 1994. 